\title{
Semicircular Duct
}

National Cancer Institute

\section{Source}

National Cancer Institute. Semicircular Duct. NCI Thesaurus. Code C33528.

The membranous tube that is located within the osseous semicircular canal. 